\title{
REMINISCENCES OF STEVE FIENBERG
}

\author{
JEROME P. REITER
}

Department of Statistical Science, Duke University

e-mail address: jreiter@duke.edu

Steve Fienberg had an enormous influence on how I think about statistical science and a huge impact on my career. Steve's research is of course legendary; he made fundamental contributions to Bayesian inference, categorical data analysis, disclosure control, official statistics, and record linkage, to name key areas where our research interests overlapped. The statistical insights in this work are brilliant and important - and directly inspired several of my papers, including my first paper in JASA. The innovations in Steve's work target and respond to real, high impact problems in official statistics with leading edge methodology intended to make it into practice. His example of being an academic statistician who improves the practice of official statisticians on the ground is one that I try to emulate in my official statistics research. Although I was not one of Steve's students, I was the beneficiary of his mentorship. At conferences and workshops, and at reciprocating visits to CMU and Duke, Steve generously gave me many hours of his time, answering questions about research, official statistics, advising students, career options and paths, and life in general. I valued his advice dearly and followed it. I also have benefitted from Steve's mentorship in a more indirect way: I have been a post-doc mentor to two of his Ph.D. students. I can say from first hand experience that Steve's students are wonderful, both as scholars and as people. As I would have expected coming from Steve's tutelage.

Jerry Reiter

Key words and phrases: reminiscences, Fienberg.

$$
\begin{array}{ll}
P_{\text {rivacy }} & \text { www.journalprivacyconfidentiality.org } \\
\text { DOl:10.29012/jpc.692 }
\end{array}
$$

This work is licensed under the Creative Commons License Attribution-NonCommercial-NoDerivatives 4.0 International (CC BY-NC-ND 4.0). To view a copy of this license, visit https : //creativecommons . org/licenses/by-nc-nd/4.0/ or send a letter to Creative Commons, 171 Second St, Suite 300, San Francisco, CA 94105, USA, or Eisenacher Strasse 2, 10777 Berlin, Germany 